\title{
Tolerance of Senecio vulgaris to Infection and Disease Caused by Native and Alien Rust Fungi
}

\author{
S. J. Inglese and N. D. Paul
}

Lancaster Environment Centre, Lancaster University, Lancaster, UK, LA1 4YQ.

Accepted for publication 8 February 2006.

\begin{abstract}
Inglese, S. J., and Paul, N. D. 2006. Tolerance of Senecio vulgaris to infection and disease caused by native and alien rust fungi. Phytopathology 96:718-726.

Plant defense strategies against pathogen attack can be divided into either resistance or tolerance. Variation in tolerance is expressed as differences in the relationship between host fitness (or yield) and the degree of infection. Plant tolerance of pathogen attack remains poorly understood both in terms of its specific mechanisms and in terms of the evolutionary processes by which it has arisen. Theoretical models predict that it is the result of coevolution between host and pathogen, suggesting greater tolerance in interactions with native as opposed to introduced pathogens.

tussilginis, which is native to the UK, and the introduced rust fungus Puccinia lagenophorae. We used the reaction norm approach to quantify tolerance and its components. The $S$. vulgaris $-C$. tussilaginis interaction expressed a significantly greater degree of tolerance, as reductions in host growth and fitness per unit infection were significantly less than with P. lagenophorae. The key mechanism for this greater tolerance to C. tussilaginis was a significantly smaller reduction in photosynthesis per unit infection than with P. lagenophorae, at both leaf and whole plant scales. There was no significant difference in the relationship between whole plant photosynthesis and host reproduction. We discuss these responses in the context of coevolution for tolerance in host-pathogen interactions.
\end{abstract} Therefore, we quantified and compared the degree of tolerance expressed in the interaction of Senecio vulgaris with the rust fungus Coleosporium
Additional keyword: parasite.
Plant defense strategies against pathogen attack can be divided into either resistance or tolerance. Variation in resistance is expressed as differences in the severity of infection, whereas variation in tolerance is expressed as differences in the relationship between host fitness (or yield) and the degree of infection (8). In comparable interactions between plants and herbivores, the evolutionary and ecological importance of tolerance and resistance have both been the subject of substantial research $(32,33)$. By contrast, tolerance in plant-pathogen interactions has been little studied compared with resistance and important questions regarding its mechanisms and evolution remain unanswered.

The terminology of tolerance remains somewhat unclear, but here we define overall tolerance as any trait (or combination of traits) that reduces or offsets the consequences of parasite attack on host fitness or yield without inhibiting parasite fitness (based on Clarke [8]). Since total lifetime fitness is not readily quantified experimentally for either host or parasite, they can be approximated using measures such as flower or seed number or reproductive dry weight for the host and, at least for leaf-infecting fungi, sporulating area for the parasite. Based on Clarke (8), overall tolerance can be divided into two components, tolerance of the parasite and tolerance of disease. Tolerance of the parasite is the relationship between the presence of the parasite and disease, where disease is strictly defined as "the malfunctioning of host cells and tissues resulting from continuous irritation by a pathogenic agent..." (1). As such, tolerance of the parasite is a function of both the capacity of the pathogen to damage host functions (which we refer to here as its pathogenicity) and the ability of the host to buffer such damage. With disease defined as above, tolerance of disease is the relationship between host growth or fitness

Correspondence author: N. D. Paul; E-mail address: n.paul@lancaster.ac.uk

DOI: 10.1094/PHYTO-96-0718

(C) 2006 The American Phytopathological Society and the malfunctioning of its normal processes resulting from infection. Clearly, the host malfunction that defines disease could be measured at a range of scales of organization but, at least for the disruption of whole plant processes such as total carbon fixation, tolerance of disease may be a function of the host's overall response to stress rather than specific to particular host-parasite interactions (7). For example, the mechanisms that buffer host fitness from loss of photosynthate may be the same whatever the cause of that loss. However, evidence from interactions between plants and foliar herbivores shows that host responses to defoliation can be specific to the herbivore or spatial pattern of damage $(10,15,18)$. By analogy, there may be elements of specificity in tolerance of disease.

The question of specificity in the expression of tolerance to pathogen attack remains unresolved. Models of host-parasite coevolution describe tolerance as the product of coevolution between host and pathogen resulting in the production of an evolutionary stable state (27). The coevolutionary hypothesis predicts specificity in tolerance and that tolerance would be more pronounced between hosts and native pathogens than between hosts and introduced pathogens. This prediction is consistent with the high degree of tolerance frequently reported between hosts and native pathogens $(27,28)$ and, conversely, the severe damage often associated with some introduced pathogens $(4,11,21)$. However, to our knowledge, this prediction has never been empirically tested and little is known about the mechanisms that would underlie such differences.

We tested the hypothesis that there is greater overall tolerance in the interaction between a host and a native pathogen than with an alien pathogen using the annual composite Senecio vulgaris. In Europe, $S$. vulgaris is attacked by both the native rust fungus Coleosporium tussilaginis and Puccinia lagenophorae, an introduced rust first recorded in the UK in the 1960s (35). Both these pathogens are nonsystemic foliar rust fungi and they provide a rare opportunity to quantify and compare tolerance of a noncrop 
host to infection by similar native and alien pathogens. Specifically, we tested the following hypotheses: (i) that overall tolerance (i.e., maintenance of fitness in relation to severity of infection) is greater in the interaction of $S$. vulgaris with $C$. tussilaginis than with $P$. lagenophorae, and (ii) given that tolerance of disease may be a function of the host's overall stress responses (described above), that greater overall tolerance to $C$. tussilaginis is the result of tolerance of the parasite rather than tolerance of disease.

Some previous studies of tolerance in plant-pathogen interactions have focused on attempts to compare plant response at identical levels of infection, which are difficult to attain $(8,29)$. Recent studies of tolerance to herbivory provide an experimental approach, the quantification of reaction norms, that addresses the perceived difficulty that tolerance of pathogen attack needs to compare responses at identical levels of infection. As described by Stowe et al. (32), the reaction norm approach requires that relative plant fitness or yield be measured against a gradient of disease or damage allowing tolerance to be expressed per unit of infection or disease. Tolerance can then be quantified by the linear function $Y=a+b X$, where $Y=$ response (e.g., relative fitness, yield, or biomass), $X=$ infection or damage level, $a=$ fitness in the absence of damage, and $b=$ the slope of the reaction norm which quantifies yield loss per unit level of disease or damage. The slope $(b)$ is thus a measure of tolerance; the less tolerant a species or genotype, the more negative the reaction norm.

The reaction norm approach has parallels in recent analyses of disease tolerance as the slope of the relationship between crop response and integrated measures of infection such as area under disease progress curve (AUDPC) (22). Similarly, the reaction norm for leaf photosynthesis is analogous to the mechanistic model of Bastiaans (6) for the relationship between visible pathogen infection and the area of photosynthetic inhibition, described as the "virtual lesion." We use the reaction norm in all our analyses because it can be applied to all elements of tolerance. In the experiments reported here, overall tolerance was calculated by the reaction norm between infection severity and whole plant dry weight and reproduction. Tolerance to infection was quantified by the reaction norm between infection severity and carbon fixation, which was chosen as a key measure of the physiological malfunction (i.e., disease) caused by rust infection. Tolerance of disease was quantified by the reaction norm between the reduction in carbon fixation and the total reproductive dry weight and whole plant dry weight of the host.

\section{MATERIALS AND METHODS}

Growth and physiological responses of $S$. vulgaris to infection by either $C$. tussilaginis or $P$. lagenophorae were measured in three repeated experiments (referred to here as experiments 1,2 , and 3), which were conducted under identical experimental conditions and in immediate succession.

Plant cultivation. Seeds of nonradiate $S$. vulgaris, which is considered very largely self-fertilized (16), were collected from stock plants grown from the seed of a single capitulum, previously collected from a wild plant from Lancaster University campus, Lancaster, UK (23). After collection, seeds were stored in the refrigerator at $4{ }^{\circ} \mathrm{C}$ for at least 2 weeks to break dormancy and then sown into seed trays containing Levington M3 compost (Fisons, UK). Trays were well watered, covered with polythene, and germinated in a controlled environment room at $16 \pm 2^{\circ} \mathrm{C}$ with a photosynthetic photon flux density of $300 \mu \mathrm{mol} \mathrm{m} \mathrm{m}^{-2} \mathrm{~s}^{-1}$ for a 16-h photoperiod. Approximately 1 week after germination, when the seedlings had produced one true leaf, seedlings of uniform size were transplanted to $9 \mathrm{~cm}$ pots containing Levington M3 potting compost and maintained under the same conditions as during germination. Plants were watered as required.

Inoculation. Plants were inoculated with either $C$. tussilaginis or P. lagenophorae 2 weeks following transplantation into pots.
Aeciospores of P. lagenophorae or urediospores of C. tussilaginis were collected from stock plants with a miniature cyclone spore collector. Stock plants had previously been infected with spores of each pathogen collected from single sporulating pustules from natural field infections of $S$. vulgaris collected in Lancaster, UK. Immediately after collection, spores were suspended in distilled water and then diluted to produce a range of three suspension concentrations that preliminary studies had shown to produce a wide range of infection densities (12). These concentrations were $0.5 \mathrm{mg} \mathrm{ml}^{-1}$ (low), $3 \mathrm{mg} \mathrm{ml}^{-1}$ (medium), and $7 \mathrm{mg} \mathrm{ml}^{-1}$ (high). A control treatment of pure water was also used giving four treatments total. Twenty-five plants per treatment were inoculated by evenly spreading the spore suspensions onto all available leaf area with a camel-hair paintbrush. Plants were then misted with distilled water, enclosed in polythene bags, and placed in darkness for $24 \mathrm{~h}$ after which they were returned to the controlled environment room. New growth without visible rust infection was inoculated on all plants 10 and 20 days after the initial inoculation, using the same method described above.

Quantification of rust infection. The appropriate measure of infection in studying tolerance has been much discussed (8). In our view, what defines tolerance, at least from the perspective of coevolution or epidemiology, is that parasite fitness is unaffected while host fitness or yield is buffered from the effects of parasite attack. In these terms, the ideal measure of the parasite is its lifetime fitness, but since this is rarely achievable in practice, we used sporulating area as an estimate of parasite fitness for these rusts. Sporulating area was measured at weekly intervals during 5 weeks following inoculation. Images of all infected leaf tissue were captured digitally and analyzed using Image Pro-Plus version 4.5 (Media Cybernetics UK, Wokingham, UK). Image analysis precisely determined percent pathogen cover by allowing sporulating pustule area to be manually selected and then measured as a proportion of the healthy green leaf area, thereby enabling calculation of percent whole plant infection and percent healthy leaf area for each individual at each harvest.

Since we relate infection to host growth and reproduction over its whole development, we used AUDPC as a measure of integrated lifetime infection. AUDPC is a convenient and commonly used measure of infection integrated over the life of a crop (9), and was calculated for the whole experiment by trapezoidal integration of weekly measurements of rust infection using the following formula:

$$
\mathrm{AUDPC}=\sum_{i=1}^{n-1}\left[\left(X_{i}+X_{i+1}\right) / 2\right] /\left(t_{i+1}-t_{i}\right)
$$

where $X_{i}$ is the percent leaf area with sporulating rust (measured as above), $n$ is the number of assessments, and $\left(t_{i+1}-t_{i}\right)$ is the interval between harvests (constant at 1 week), giving units of percent infection weeks.

Growth analysis. Five replicate plants per treatment were harvested 1 day prior to the first inoculation and then weekly for 5 weeks following inoculation. Plants were divided into their constituent organs of leaves, stems, roots, and reproductive tissues. Reproductive tissues were further divided into yellow capitula (those with florets and stamens exposed) and mature capitula (those with seed set and matured). Floret production is well correlated with mature seed production (24). Leaves were divided into infected (those with any visible signs of infection) and noninfected leaves, and their area was measured with a leaf area meter (model 3100, Li-Cor, Lincoln, NE). Roots were recovered from the pots and separated from the soil by washing with water. All plant material was placed in a drying oven at $80^{\circ} \mathrm{C}$ until it reached constant mass, and then dry mass for each tissue type was recorded. In experiment 2 only, five seed bearing capitula per plant were collected at the final harvest, and the number and mass of these seeds were measured. From these data, 100 seed mass for each individual was calculated, and total seed number produced 
was estimated by multiplying the average number of seed per capitulum by the total number of mature capitula on the plant. After capitula have matured and the seed dispersed, the mature capitula remain on the plant. Hence, the number recorded at the final harvest is an accurate measure of the total number of capitula that have reached maturity and dispersed seed up until that point.

Gas exchange. As noted above, whole plant carbon fixation was chosen as an integrated measure of the physiological malfunction (i.e., disease) caused by rust infection. Direct measurements of whole plant carbon fixation have the advantages of integrating responses across all leaves, uninfected or asymptomatic as well as infected, different leaf ages, etc. Such measurements, while key to understanding whole plant response, clearly do not provide any understanding of local responses to infection in specific leaves. Thus, we also measured leaf scale photosynthesis in both infected leaves, and in asymptomatic leaves on infected plants.

Whole plant $\mathrm{CO}_{2}$ and $\mathrm{H}_{2} \mathrm{O}$ exchanges were measured in all plants prior to the weekly destructive harvest detailed above. The whole shoot system was enclosed within a 20-liter transparent Perspex box that enabled pots and roots to be excluded from the chamber, and gas exchanges were measured with a CIRAS 1 infrared gas analyzer (IRGA) (PP Systems Ltd., Hitchin, UK). Ambient air from outside the laboratory was used as stable reference supply and air was mixed within the cuvette with a fan. Measurements were made under a $400 \mathrm{~W}$ metal halide lamp giving a photosynthetic photon flux density of $250 \mu \mathrm{mol} \mathrm{m} \mathrm{m}^{-2} \mathrm{~s}^{-1}$. Each plant was placed in the measurement chamber and allowed to equilibrate for $5 \mathrm{~min}$, gas exchange was measured every $30 \mathrm{~s}$ for $10 \mathrm{~min}$, and the mean of these 20 measurements was determined. Plants were blocked by treatment to eliminate any effects of time of day. Whole plant transpiration and photosynthesis were initially recorded as mmol $\mathrm{H}_{2} \mathrm{O} \mathrm{s}^{-1}$ plant $^{-1}$ and $\mu \mathrm{mol} \mathrm{CO}_{2} \mathrm{~s}^{-1}$ plant ${ }^{-1}$, respectively. After leaf area was determined, these values were expressed as $\mathrm{mmol} \mathrm{H}_{2} \mathrm{O} \mathrm{m}^{-2} \mathrm{~s}^{-1}$ and $\mu \mathrm{mol} \mathrm{CO}_{2} \mathrm{~m}^{-2} \mathrm{~s}^{-1}$ to give mean canopy gas exchange averaged per square meter of leaf area per second. This was converted to a daily rate by multiplication by 60 , then by 60 again to give gas exchange per hour, and then by the 16-h photoperiod to give an estimation of moles of gas exchanged per day. Multiplication by 7 enabled estimation of total moles of $\mathrm{H}_{2} \mathrm{O}$ transpired per square meter and total moles of $\mathrm{CO}_{2}$ fixed per square meter per individual per week based on the assumption that the rates of gas exchange measured were both constant and indicative of that over the entire week. Cumulative moles of $\mathrm{H}_{2} \mathrm{O}$ transpired and $\mathrm{CO}_{2}$ fixed for each individual at the final harvest were then estimated by calculating the sum of the weekly values.

Whole plant gas exchange in darkness was measured for plants of both pathogen treatments in experiment 2. Exactly the same method of measurement was used as in the light, but plants were confined to darkness for $3 \mathrm{~h}$ prior to measurement, and measurement was undertaken with light excluded from the measurement chamber.

Individual leaf gas exchange was measured for both pathogens in experiments 2 and 3 . The third fully expanded leaf on all plants was marked prior to inoculation and these leaves were measured weekly using a CIRAS 1 IRGA (PP Systems). Gas exchange was measured at cuvette conditions of saturated light, $80 \%$ ambient humidity, and $360 \mathrm{ppm}$ of $\mathrm{CO}_{2}$. Leaves were placed in the cuvette, allowed to equilibrate for $5 \mathrm{~min}$, and measured every $30 \mathrm{~s}$ for $5 \mathrm{~min}$. The means of these measurements were determined. Leaf gas exchanges were measured in the same way in darkness. Plants were placed in darkness $3 \mathrm{~h}$ prior to measurement, and then gas exchange was measured with light excluded from the leaf surface. Leaf gas exchanges were related to infection assessed weekly on the measured leaves using the same method as whole plant infection assessment.

Statistical analysis. A three-way analysis of variance with experiment, rust, and severity of infection as the main factors showed no significant effect of experiment or its interactions. Hence, data across the three experiments were pooled into a single data set for each pathogen, and then tolerance of $S$. vulgaris to each was measured using the reaction norm approach described earlier. This was done using GraphPad Prism 4 (GraphPad Software, San Diego, CA), with which host growth and physiological responses were regressed against infection severity measured as AUDPC. The slope of the relationships with each rust was taken as the measure of tolerance, and an $F$ test of difference in the slopes was computed to determine whether the extent of tolerance differed significantly between pathogens.

\section{RESULTS}

Infection development and severity of the pathogens. For both pathogens, infection significantly increased with spore concentration to produce a gradient of infection (Fig. 1). This was

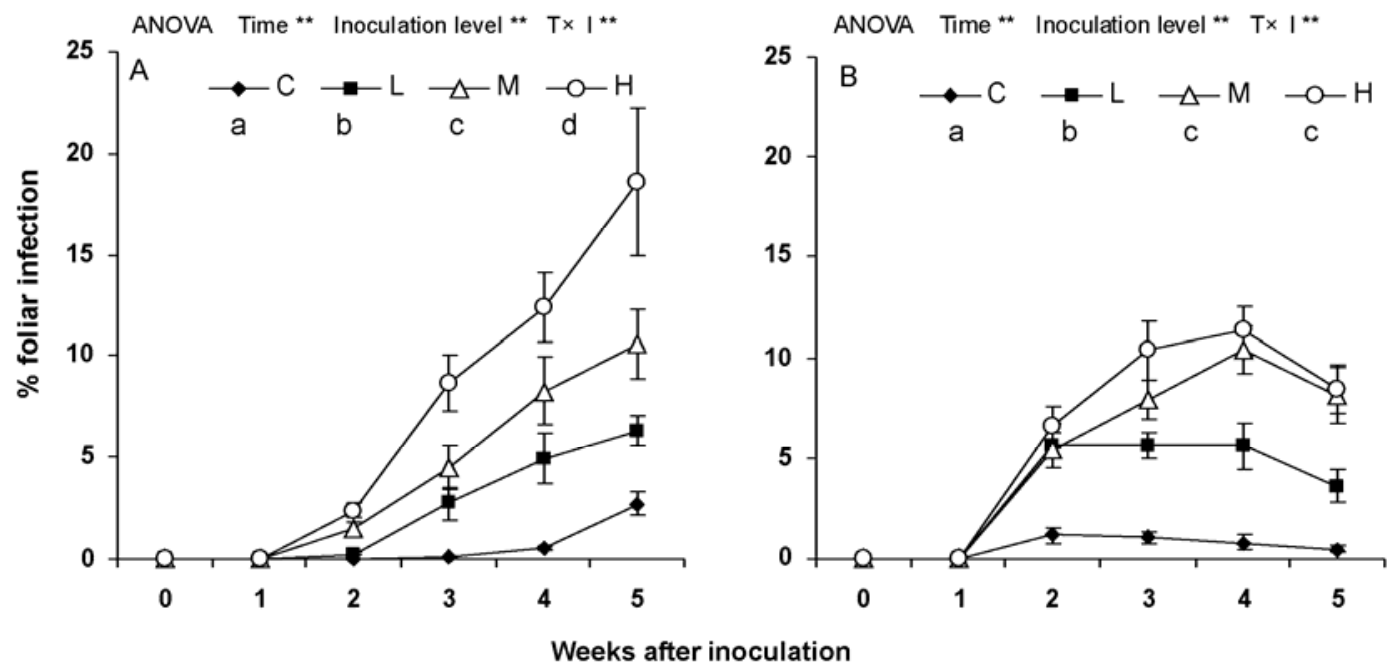

Fig. 1. Foliar infection of Senecio vulgaris produced by treatment with spore suspensions of $0,0.5,3$, and $7 \mathrm{mg} \mathrm{ml}^{-1}$ of $\mathbf{A}$, Coleosporium tussilaginis and $\mathbf{B}$, Puccinia lagenophorae. Data are means of 15 replicates and error bars indicate standard errors. The results of two-way analysis of variance (ANOVA) are shown, where $*$ and $* *$ represent significant effects at $P<0.05$ and 0.01 , respectively. The results of post-hoc comparison for inoculation treatment are also shown. Treatments that do not share the same letter are significantly different at $P<0.05$. C, L, M, and $\mathrm{H}$ represent control, low, medium, and high spore densities, respectively (details are provide in the text). 
evident both in terms of mean foliar infection (Fig. 1, $P=0.007$ for $C$. tussilaginis, $P=0.01$ for $P$. lagenophorae) and in terms of integrated cumulative infection measured as AUDPC. The range of AUDPC produced was almost identical for the two pathogens, ranging from 0.17 to $55.9 \%$ infection weeks for $C$. tussilaginis and from 0.017 to $53.4 \%$ infection weeks for P. lagenophorae. Average foliar infection was also very similar between pathogens, the mean AUDPC across all treatments being 17.71 and $19.4 \%$ infection weeks for $C$. tussilaginis and P. lagenophorae, respectively.

Overall tolerance: relationship between rust infection and host growth and fitness. There were significant linear relationships between infection of both pathogens and various growth parameters of $S$. vulgaris. Increasing AUDPC resulted in reduced final whole plant dry weight with both pathogens (Fig. 2A, both $P<0.001$ ), but this effect was significantly greater with $P$. lagenophorae, as the slope of the reaction norm was significantly $(P<$ $0.01)$ more negative (Fig. 2A). This difference was reflected in individual vegetative tissue types: $P$. lagenophorae reduced root dry weight and stem dry weight by over twice that caused by equivalent levels of $C$. tussilaginis infection ( $F$ test for a difference in slopes for roots $[P=0.001]$ and stems $[P<0.001]$; data not shown).

$P$. lagenophorae was also more deleterious to reproductive growth. Although there was a significant negative linear relationship between final total reproductive dry weight and infection for both pathogens (Fig. 2B, both $P<0.001$ ), the significant difference in the slopes of these reaction norms $(P=0.001)$
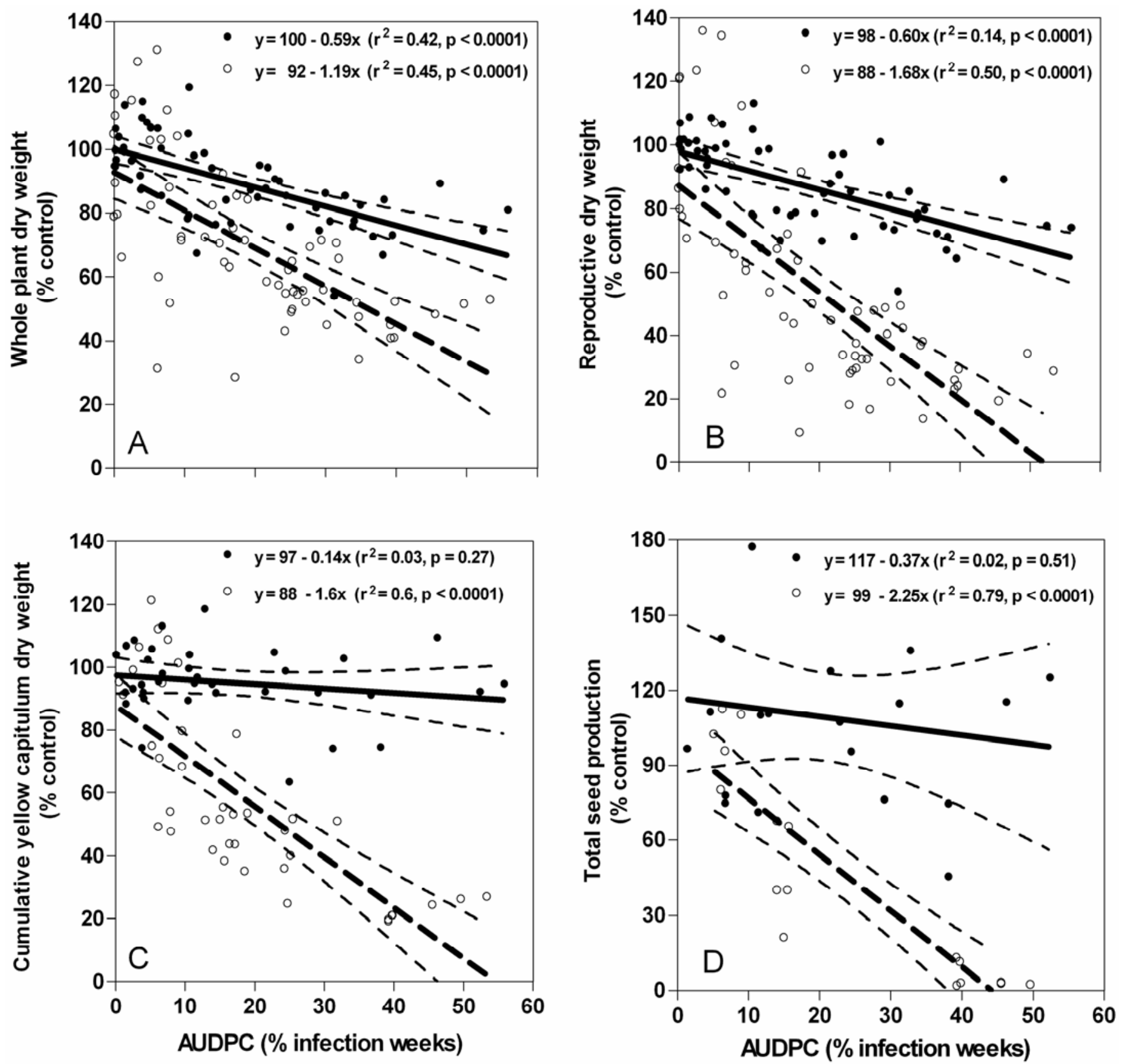

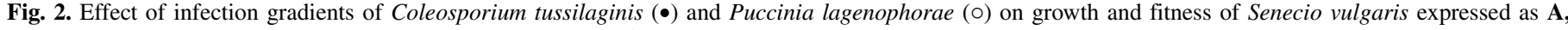

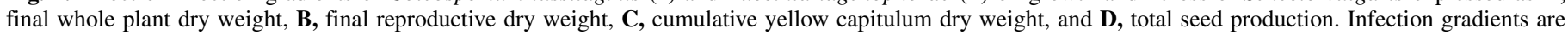

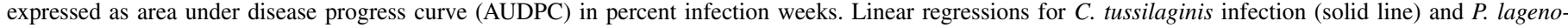

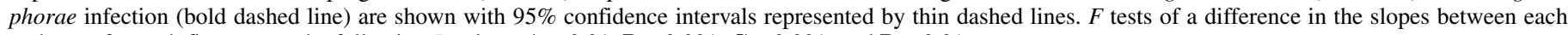
pathogen for each figure gave the following $P$ values: $\mathbf{A},<0.01 ; \mathbf{B},<0.001 ; \mathbf{C},<0.001 ;$ and $\mathbf{D},<0.01$. 

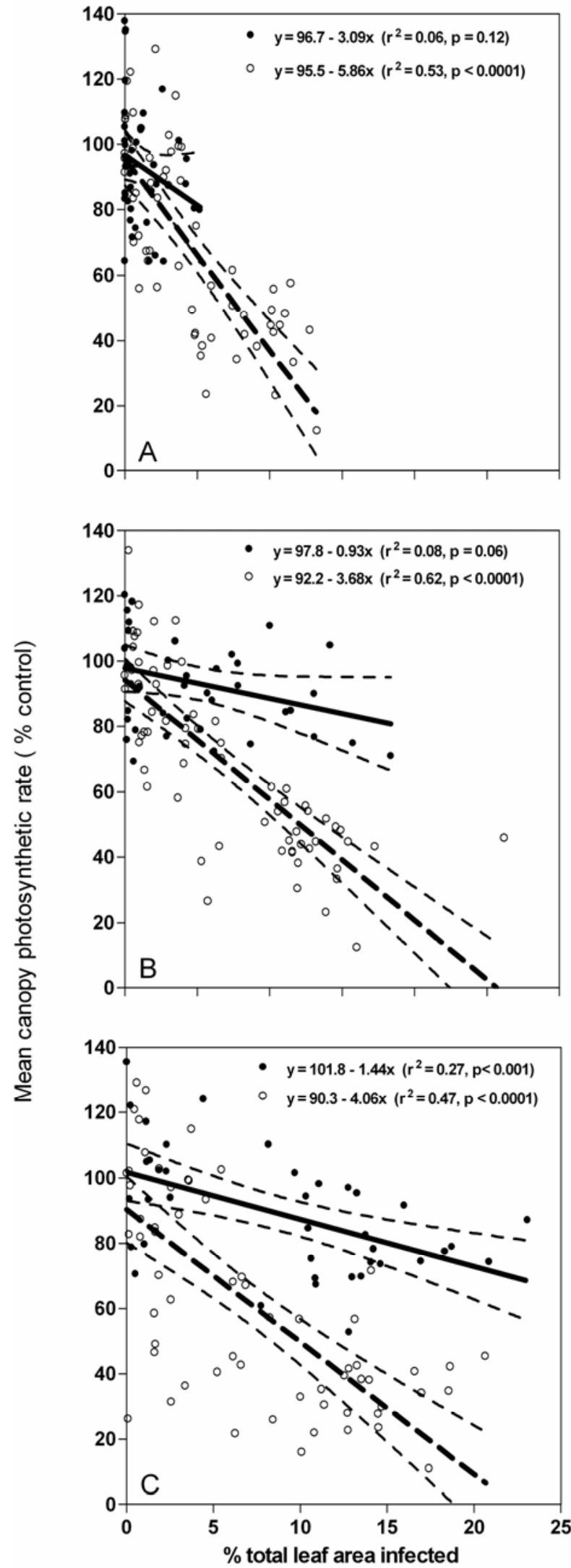

Fig. 3. Effect on infection gradients of Coleosporium tussilaginis $(\bullet)$ and Puccinia lagenophorae (०) on mean canopy carbon fixation rate $\left(\mu\right.$ mole $\mathrm{CO}_{2}$ $\mathrm{m}^{-2} \mathrm{~s}^{-1}$ ) of Senecio vulgaris at A, 2 weeks, $\mathbf{B}, 3$ weeks, and $\mathbf{C}, 4$ weeks after inoculation. Linear regressions for C. tussilaginis infection (solid line) and P. lagenophorae infection (bold dashed line) are shown with 5\% confidence intervals represented by thin dashed lines. $F$ tests of a difference in the slopes between each pathogen for each figure gave the following $P$ values: A, 0.23; $\mathbf{B},<0.001$; and $\mathbf{C},<0.001$. showed that, per unit AUDPC, P. lagenophorae was approximately three times more damaging than $C$. tussilaginis. The more severe effects of $P$. lagenophorae were even more apparent in other reproductive measures. There was a significant difference between the effects of the two pathogens on cumulative yellow capitulum production (Fig. 2C, $P<0.001$ ) and seed production (Fig. 2D, $P<0.001$ ). C. tussilaginis had no significant effect on either parameter (Fig. $2 \mathrm{C}, P=0.27$; Fig. $2 \mathrm{D}, P=0.51$ ) in contrast to equivalent infection severities of $P$. lagenophorae which severely reduced both (Fig. 2C, $P<0.001$; Fig. $2 \mathrm{D}, P<$ $0.001)$. Effects of $P$. lagenophorae were so severe that maximum infection resulted in a reduction of total cumulative yellow capitulum dry weight of around $80 \%$, and seed production was almost eliminated.

Tolerance of the parasite: relationship between rust infection and $\mathrm{CO}_{2}$ exchanges in $\mathrm{S}$. vulgaris. At 2 weeks following inoculation (Fig. 3A), infection of $C$. tussilaginis caused no significant effect on mean canopy photosynthetic rate, whereas infection of $P$. lagenophorae caused a significant decrease. At 3 and 4 weeks following inoculation (Fig. 3B and C), there were significant negative linear relationships between percent whole plant infection and mean canopy photosynthetic rate for both rusts. However, the effect of $P$. lagenophorae was over twice as severe as that of $C$. tussilaginis, and this difference was highly significant at both 3 weeks and 4 weeks following inoculation (Fig. 3B, $P<0.001$; Fig. 3C, $P<0.001)$. These more severe effects of $P$. lagenophorae highlighted by the weekly measurements were reflected by calculated cumulative moles of $\mathrm{CO}_{2}$ fixed over the 5-week experimental period. Reaction norms for both pathogens showed significant negative linear relationships between cumulative infection and cumulative carbon fixation (Fig. 4A, C. tussilaginis $[P=0.0006]$ and $P$. lagenophorae $[P<0.0001])$, but per unit AUDPC, the effects of $P$. lagenophorae were around four times greater (Fig. 4A, $P<0.0001$ ). Such effects were not apparent during darkness when neither pathogen had any significant effect on cumulative whole plant carbon exchange, indicated by the nonsignificant reaction norms (Fig. 4B).

On a single leaf scale, $P$. lagenophorae was, again, more detrimental to carbon fixation. At 2, 3, and 4 weeks following inoculation, both pathogens significantly reduced leaf scale $\mathrm{CO}_{2}$ fixation (Fig. 5A, C, and E, respectively) but consistently to a significantly greater extent with equivalent severity of $P$. lagenophorae infection (Fig. 5A, C, and E, respectively, $P=0.045, P<0.0001$, and $P=0.001$, respectively). At 2 weeks following inoculation, the relative deleterious effect of $P$. lagenophorae was around twice that of $C$. tussilaginis (Fig. 5A, $P=0.045$ ); this increased to over three times after 3 weeks (Fig. 5C, $P<0.0001$ ), and then to four times more detrimental at 4 weeks following inoculation (Fig. 5E, $P=0.001$ ). In darkness, differences between the effects of the pathogens were less evident. Although $C$. tussilaginis caused an initially greater effect on dark respiration at 2 weeks following inoculation (Fig. 5B, $P<0.0001$ ), this difference was transient and disappeared at 3 weeks (Fig. 5D, $P=0.31$ ) and 4 weeks (Fig. 5F, $P=0.43$ ) after inoculation when both caused equivalent increases in dark respiration.

Tolerance of disease: relationship between reduced carbon fixation and host growth or fitness. Pathogen-driven reductions in integrated mean canopy carbon fixation were significantly negatively related to whole plant dry weight (Fig. 6A, C. tussilaginis $[P=0.019]$ and $P$. lagenophorae $[P<0.001])$ and total reproductive dry weight (Fig. 6B, C. tussilaginis $[P=$ $0.001]$ and $P$. lagenophorae $[P<0.001])$. There was a tendency for the slopes of the reactions norms to be steeper for $P$. lagenophorae than for $C$. tussilaginis but the differences were not significant for either whole plant dry weight (Fig. 6A, $P=0.43$ ) or final reproductive dry weight (Fig. 6B, $P=0.1$ ). Thus, there were no significant differences in tolerance to disease in the two systems. 


\section{DISCUSSION}

The reaction norm approach provided a convenient method of evaluating and comparing tolerance by quantification of host responses to a gradient of infection of each pathogen, an approach that negated the need for the production of identical infection severities, which is extremely difficult in practice (8). Instead, similar gradients of infection were achieved by different inoculum loads. The range of infection was comparable for the two pathogens, as measured by AUDPC, which is extensively used as a measure of integrated infection (13). Regression of whole plant dry weight and total reproductive dry weight against these infection gradients produced significantly more negative reaction norms with infection of $P$. lagenophorae than with $C$. tussilaginis. The negative effect of $P$. lagenophorae was twice as great with regard to whole plant dry weight, and three times greater on total reproductive dry weight. It is clear that $S$. vulgaris is more tolerant of infection by $C$. tussilaginis than by P. lagenophorae.

The mechanisms by which this difference in overall tolerance was produced were dissected by quantification of its components, tolerance of the parasite and tolerance of disease. Tolerance of the parasite was measured by relating infection severity to the degree of disease produced, here quantified as the percent reduction in integrated canopy photosynthesis (i.e., total moles of $\mathrm{CO}_{2}$ fixed per unit leaf area over the whole life of the plant). It has been well established that infection of biotrophic pathogens generally results in the inhibition of photosynthesis and increased dark respiration (5). However, unlike the majority of studies which have shown this in only single leaves $(2,29)$, it was shown here that infection by both pathogens caused significant decreases in photosynthesis on a whole plant scale. P. lagenophorae caused decreases in whole plant photosynthetic rate per unit infection up to four times greater than those caused by $C$. tussilaginis. There is significantly greater tolerance of the parasite in the interaction between $S$. vulgaris and $C$. tussilaginis than that with $P$. lagenophorae. This can be restated as infection by $P$. lagenophorae causes greater disease, defined as the physiological malfunction evident in reduced carbon fixation, than infection by $C$. tussilaginis. It has been shown in other systems that plants can compensate for reduced $\mathrm{CO}_{2}$ fixation in infected tissues by increased photosynthesis either in healthy parts of infected leaves $(30,31)$ or in uninfected leaves $(20,25,26)$. Leaf measurements of uninfected leaves on infected plants revealed that photosynthetic changes in healthy leaves were complex and varied with leaf age and the duration of infection (12), but evidence for compensatory photosynthesis in uninfected leaves was confined to plants infected with $P$. lagenophorae. For example, 4 weeks after infection, photosynthetic rates in uninfected leaves were $4.49 \pm 0.51 \mu \mathrm{mol}$ $\mathrm{CO}_{2} \mathrm{~m}^{-2} \mathrm{~s}^{-1}$ in control plants, $4.30 \pm 0.70 \mu \mathrm{mol} \mathrm{CO}_{2} \mathrm{~m}^{-2} \mathrm{~s}^{-1}$ in plants infected with $C$. tussilaginis $(P>0.05)$, and $6.86 \pm$ $0.62 \mu \mathrm{mol} \mathrm{CO}_{2} \mathrm{~m}^{-2} \mathrm{~s}^{-1}$ in plants infected with $P$. lagenophorae ( $P<0.05$ compared with controls). This is consistent with previous reports of compensatory photosynthesis in plants infected with $P$. lagenophorae (23). Measurement of infected leaves showed that despite heavy infection with $C$. tussilaginis, where up to $60 \%$ of the leaf was visibly infected, photosynthesis was maintained at over $50 \%$ of the control rate. In contrast, similar or smaller infection with $P$. lagenophorae caused a complete loss of net carbon fixation. Therefore, it was maintenance of photosynthesis in infected leaves, and not compensatory photosynthesis in uninfected leaves, that minimized disease expression and conferred high tolerance of the parasite in the S. vulgaris-C. tussilaginis interaction.

Although the reaction norms between disease (measured as reduced $\mathrm{CO}_{2}$ fixation) and whole plant and total reproductive dry weight tended to be more negative for $P$. lagenophorae than for C. tussilaginis, these differences were not statistically significant (Fig. 6). Thus, there is no evidence for differences in tolerance of disease between the two pathosystems. Therefore, the greater overall tolerance observed in the $S$. vulgaris-C. tussilaginis interaction was due to the greater tolerance of the parasite, not greater tolerance of disease. As discussed, the high tolerance of the parasite was due to the ability of $S$. vulgaris to maintain photosynthesis in leaves heavily infected with $C$. tussilaginis. The basis of
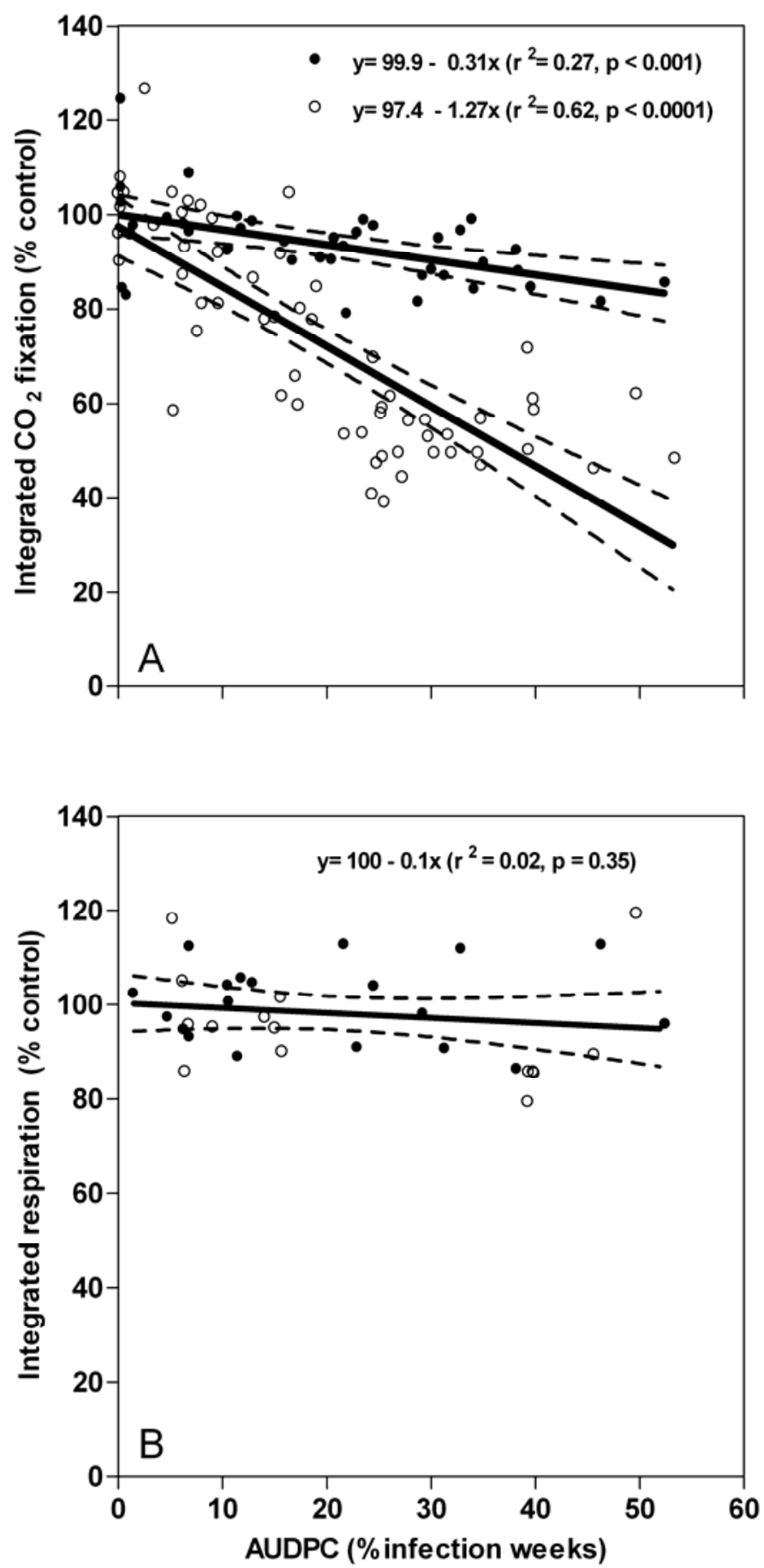

Fig. 4. Effect on infection gradients of Coleosporium tussilaginis (•) and Puccinia lagenophorae (O) on calculated integrated carbon exchange of Senecio vulgaris expressed as $\mathbf{A}$, total moles of $\mathrm{CO}_{2}$ fixed during light, and $\mathbf{B}$, total moles of $\mathrm{CO}_{2}$ respired during darkness. Infection gradients are expressed as area under disease progress curve (AUDPC) in percent infection weeks. Linear regressions for $C$. tussilaginis infection (solid line) and P. lagenophorae infection (bold dashed line) are shown with $5 \%$ confidence intervals represented by thin dashed lines. $F$ tests of a difference in the slopes between each pathogen for each figure gave the following $P$ values: $\mathbf{A},<0.001$ and $\mathbf{B}$, 0.48 . Since there was no significant difference between the effects of each rust on respiration, data have been pooled to give a single reaction norm. 

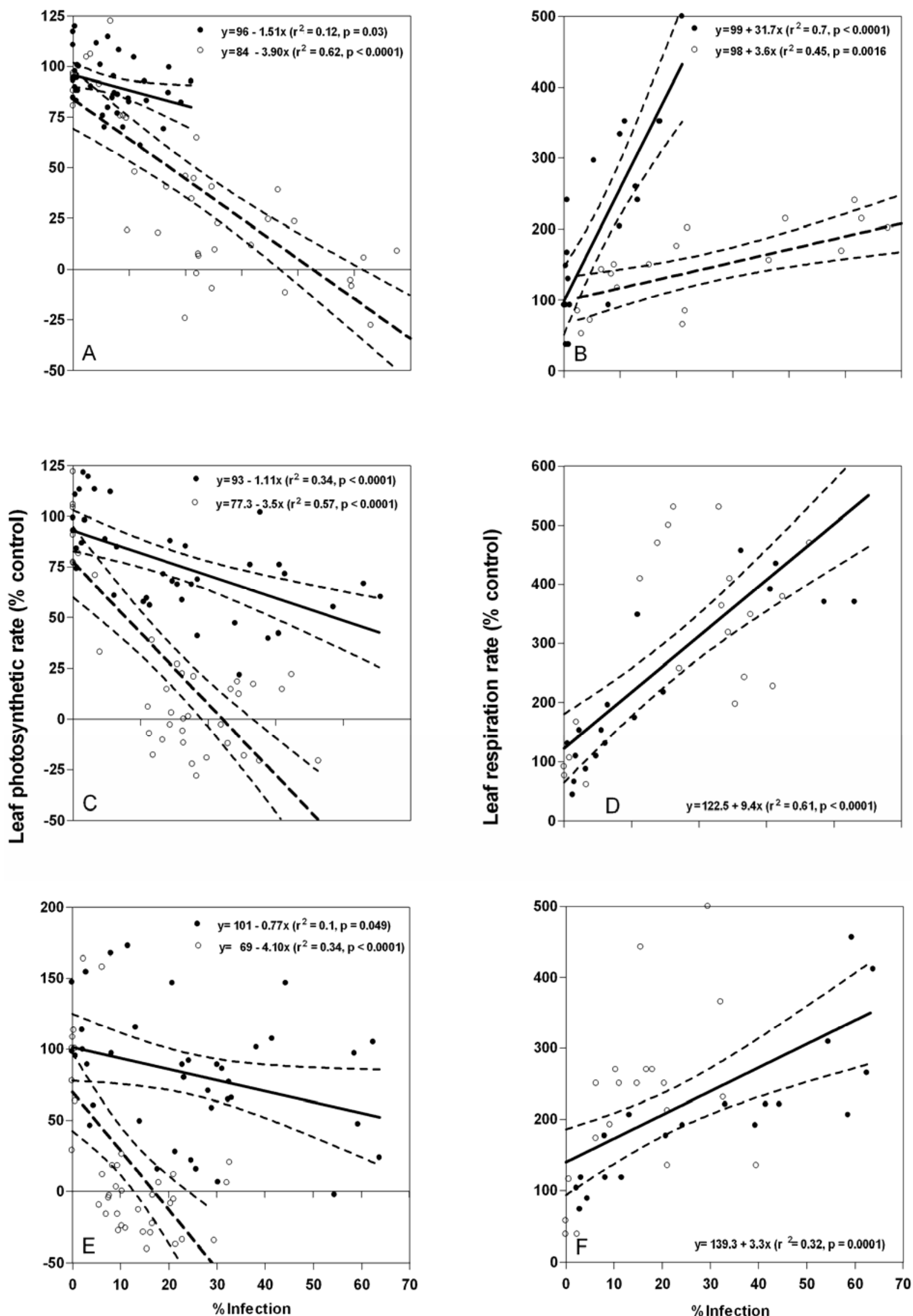

Fig. 5. Effect on leaf infection severity of Coleosporium tussilaginis (•) and Puccinia lagenophorae ( $(0)$ on single leaf carbon exchange of Senecio vulgaris in light $(\mathbf{A}, \mathbf{C}$, and $\mathbf{E})$ and darkness $(\mathbf{B}, \mathbf{D}$, and $\mathbf{F})$ at $\mathbf{A}$ and $\mathbf{B}, 2$ weeks following inoculation, $\mathbf{C}$ and $\mathbf{D}, 3$ weeks following inoculation, and $\mathbf{E}$ and $\mathbf{F}, 4$ weeks following inoculation. Linear regressions for $C$. tussilaginis infection (solid line) and P. lagenophorae infection (bold dashed line) are shown with 5\% confidence intervals represented by thin dashed lines. $F$ tests of a difference in the slopes between each pathogen for each figure gave the following $P$ values: A, $0.045 ; \mathbf{B},<0.001$; $\mathbf{C},<0.001 ; \mathbf{D}, 0.31 ; \mathbf{E}, 0.001 ;$ and $\mathbf{F}, 0.43$. Where there is no significant difference between the rusts, data sets have been pooled to give a single reaction norm. 
this greater tolerance of the parasite in terms of leaf scale photosynthesis is currently being investigated. However, it is unlikely to be due simply to greater fungal respiration in P. lagenophorae, since this would have been reflected in leaf respiration rates (14), and we found no such difference between the two pathogens (Fig. 5). Secondly, microscopic examination of stained leaves suggested that there was no gross difference in the relationship between visible sporulation and the area of leaf colonized by fungi (12). It is more likely that the greater effect of P. lagenophorae is a function of mechanisms not directly associated with pathogen growth or metabolism, a finding analogous with a recent investigation into the effects of herbivores on leaf gas exchange (3). As
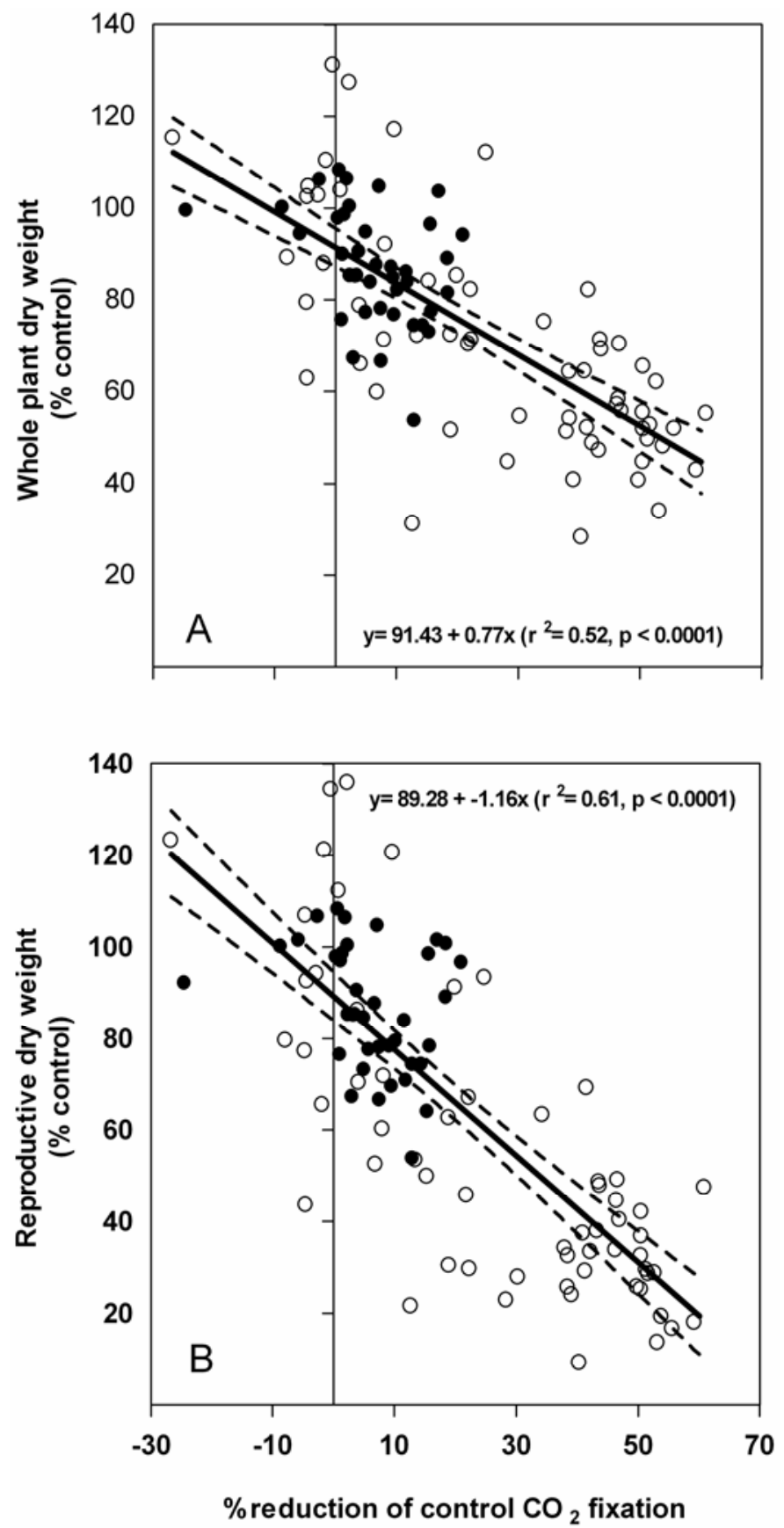

Fig. 6. Relationship between reduction in total moles of $\mathrm{CO}_{2}$ fixed per plant per $\mathrm{m}^{-2}$ of leaf area and $\mathbf{A}$, whole plant dry weight and $\mathbf{B}$, reproductive dry weight for Coleosporium tussilaginis ( $\bullet$ ) and Puccinia lagenophorae (०). Since there was no significant difference between the relationship of severity of each rust and whole plant dry weight $(P=0.43)$ or reproductive dry weight $(P=0.1)$, data for each pathogen have been pooled to give a single reaction norm for each growth response. noted above, the virtual lesion model (6) offers an alternative approach to analyzing our leaf photosynthesis data, with the ratio of the area of the virtual lesion to the visible lesion (the parameter beta in Bastiaans' [6] model) being broadly comparable with the slope of the reaction norm. Analysis of our data using the virtual lesion model gave values for beta for $P$. lagenophorae that were 5- to 30-fold higher than for C. tussilaginis (S. J. Inglese and N. D. Paul, unpublished data), confirming the far greater effects of $P$. lagenophorae apparent in the reaction norm analysis. Certainly, our results suggest that pathogen attributes are an important determinant in the expression of tolerance in host pathogen associations. This observation is consistent with studies in herbivory which have shown that host responses to equivalent levels of herbivore-induced damage can be specific to the herbivore or pattern of damage $(10,15,18)$.

These data confirm our hypothesis that overall tolerance is greater in the interaction of $S$. vulgaris with $C$. tussilaginis than with $P$. lagenophorae, and demonstrate that this difference is a function of tolerance of the parasite not tolerance of disease. The mechanisms by which photosynthesis in $S$. vulgaris is better buffered against infection by $C$. tussilaginis than $P$. lagenophorae remain unknown, but if we take pathogenicity as being the ability of a parasite to interfere with one or more of the essential functions of the plant, thereby causing disease (1), then P. lagenophorae has greater pathogenicity than $C$. tussilaginis. Clearly, there may be inherent differences between these two rusts that are unrelated to their coevolutionary history with $S$. vulgaris, but these data are at least consistent with the broader hypothesis that tolerance is coevolved between host and pathogen. Testing this hypothesis is limited partly because tolerance remains poorly understood, even with crop pathogens, and partly because pathosystems that allow direct comparison of alien and native pathogens on noncrop hosts are rare. One source of analogous interactions may come from wild plants introduced outside their native range. In such systems, understanding of tolerance would be directly relevant to the enemy escape hypothesis that predicts that invasiveness is a function of evasion of parasites from their native range $(17,34)$, and may also be pertinent to the development of biological control strategies for alien weeds (19).

\section{ACKNOWLEDGMENTS}

We thank the Natural Environment Research Council for a Ph.D. studentship awarded to S. J. Inglese; R. Handley, P. Kover, Y. CachuPavon, and two anonymous referees for their comments on the manuscript; and P. Smith for technical support.

\section{LITERATURE CITED}

1. Agrios, G. N. 2005. Plant Pathology. Elsevier Academic Press, Burlington, MA.

2. Akhkha, A., Clarke, D. D., and Dominy, P. J. 2003. Relative tolerances of wild and cultivated barley to infection by Blumeria graminis f. sp. hordei (syn. Erysiphe graminis f. sp. hordei). II. The effects of infection on photosynthesis and respiration. Physiol. Mol. Plant Pathol. 62:347-354.

3. Aldea, M., Hamilton, J. G., Resti, J. P., Zangerl, A. R., Berenbaum, M. R., and DeLucia, E. H. 2005. Indirect effects of insect herbivory on leaf gas exchange in soybean. Plant Cell Environ. 28:402-411.

4. Anderson, P. K., Cunningham, A. A., Patel, N. G., Morales, F. J., Epstein, P. R., and Daszak, P. 2004. Emerging infectious diseases of plants: Pathogen pollution, climate change and agrotechnology drivers. Trends Ecol. Evol. 19:535-544.

5. Ayres, P. G. 1978. $\mathrm{CO}_{2}$ exchanges in plants infected by obligately biotrophic pathogens. Pages 343-354 in: Photosynthesis and Plant Development. R. Marchelle, H. Clijsters, and M. Van Pouke, eds. Dr. W. Junk, London.

6. Bastiaans, L. 1991. Ratio between virtual and visual lesion size as a measure to describe reduction in leaf photosynthesis of rice due to leaf blast. Phytopathology 81:611-615.

7. Belsky, A. J., Carson, W. P., Jensen, C. L., and Fox, G. A. 1993. Overcompensation by plants-Herbivore optimization or Red Herring. Evol. Ecol. 7:109-121. 
8. Clarke, D. D. 1986. Tolerance of parasites and disease in plants and its significance in host-parasite interactions. Adv. Plant Pathol. 5:161-197.

9. Danielsen, S., and Munk, L. 2004. Evaluation of disease assessment methods in quinoa for their ability to predict yield loss caused by downy mildew. Crop Prot. 23:219-228.

10. Gavloski, J. E., and Lamb, R. J. 2000. Compensation for herbivory in cruciferous plants: Specific responses to three defoliating insects. Environ. Entomol. 29:1258-1267.

11. Holdenrieder, O., Pautasso, M., Weisberg, P. J., and Lonsdale, D. 2004. Tree diseases and landscape processes: The challenge of landscape pathology. Trends Ecol. Evol. 19:446-452.

12. Inglese, S. J. 2005. Tolerance of Senecio vulgaris attacked by a native and an alien pathogen. Lancaster University, Lancaster.

13. Jeger, M. J., and Viljanen-Rollinson, S. L. H. 2001. The use of the area under the disease-progress curve (AUDPC) to assess quantitative disease resistance in crop cultivars. Theor. Appl. Genet. 102:32-40.

14. Kneale, J., and Farrar, J. F. 1985. The localization and frequency of haustoria in colonies of brown rust on barley leaves. New Phytol. 101:495-505.

15. Marquis, R. J. 1992. A bite is a bite is a bite-Constraints on response to folivory in Piper arieianum (Piperaceae). Ecology 73:143-152.

16. Marshall, D. F., and Abbott, R. J. 1982. Polymorphism for outcrossing frequency at the ray floret locus in Senecio vulgaris L. 1. Evidence. Heredity 48:227-235.

17. Mitchell, C. E., and Power, A. G. 2003. Release of invasive plants from fungal and viral pathogens. Nature 421:625-627.

18. Morrison, K. D., and Reekie, E. G. 1995. Pattern of defoliation and its effect on photosynthetic capacity in Oenothera biennis. J. Ecol. 83:759-767.

19. Muller-Scharer, H., Schaffner, U., and Steinger, T. 2004. Evolution in invasive plants: Implications for biological control. Trends Ecol. Evol. 19:417-422.

20. Murray, D. C., and Walters, D. R. 1992. Increased photosynthesis and resistance to rust infection in upper, uninfected leaves of rusted broad bean (Vicia faba L.). New Phytol. 120:235-242.

21. Newhook, F. J., and Podger, F. D. 1972. Role of Phytophthora cinnamomi in Australian and New Zealand Forests. Annu. Rev. Phytopathol. 10:299-326.

22. Parker, S. R., Welham, S., Paveley, N. D., Foulkes, J., and Scott, R. K. 2004. Tolerance of Septoria leaf blotch in winter wheat. Plant Pathol. 53:1-10.
23. Paul, N. D., and Ayres, P. G. 1984. Effects of rust and post-infection drought on photosynthesis, growth and water relations in groundsel. Plant Pathol. 33:561-569.

24. Paul, N. D., and Ayres, P. G. 1987. Survival, growth and reproduction of groundsel (Senecio vulgaris) infected by rust (Puccinia lagenophorae) in the field during summer. J. Ecol. 75:61-71.

25. Roberts, A. M., and Walters, D. R. 1988. Photosynthesis in discrete regions of leek leaves infected with the rust, Puccinia-allii Rud. New Phytol. 110:371-376.

26. Rooney, J. M., and Hoad, G. V. 1989. Compensation in growth and photosynthesis of wheat (Triticum aestivum L.) following early inoculations with Septoria nodorum (Berk) Berk. New Phytol. 113:513-521.

27. Roy, B. A., and Kirchner, J. W. 2000. Evolutionary dynamics of pathogen resistance and tolerance. Evolution 54:51-63.

28. Roy, B. A., Kirchner, J. W., Christian, C. E., and Rose, L. E. 2000. High disease incidence and apparent disease tolerance in a North American Great Basin plant community. Evol. Ecol. 14:421-438.

29. Sabri, N., Dominy, P. J., and Clarke, D. D. 1997. The relative tolerances of wild and cultivated oats to infection by Erysiphe graminis f. sp. avenae. 2. The effects of infection on photosynthesis and respiration. Physiol. Mol. Plant Pathol. 50:321-335.

30. Scholes, J. D., and Farrar, J. F. 1986. Increased rates of photosynthesis in localized regions of a barley leaf infected with brown rust. New Phytol. 104:601-612.

31. Scholes, J. D., and Rolfe, S. A. 1996. Photosynthesis in localized regions of oat leaves infected with crown rust (Puccinia coronata): Quantitative imaging of chlorophyll fluorescence. Planta 199:573-582.

32. Stowe, K. A., Marquis, R. J., Hochwender, C. G., and Simms, E. L. 2000. The evolutionary ecology of tolerance to consumer damage. Annu. Rev. Ecol. Syst. 31:565-595.

33. Strauss, S. Y., and Agrawal, A. A. 1999. The ecology and evolution of plant tolerance to herbivory. Trends Ecol. Evol. 14:179-185.

34. Torchin, M. E., Lafferty, K. D., Dobson, A. P., McKenzie, V. J., and Kuris, A. M. 2003. Introduced species and their missing parasites. Nature 421:628-630.

35. Wilson, I. M., Walshaw, D. F., and Walker, J. 1965. New groundsel rust in Britain and its relationship to certain Australasian rusts. Br. Mycol. Soc. Trans. 48:501-511. 